\title{
SAS Ophthalmologist: my positive career choice
}

\author{
Bronwen Attrup ${ }^{1}$
}

Received: 22 February 2019 / Accepted: 22 February 2019 / Published online: 29 March 2019

(c) The Royal College of Ophthalmologists 2019

For many consultants, trainees and managers, the career path and work of an SAS (Specialty and Associate Specialist) doctor can seem confusing, particularly because the grade is so diverse in skills and experience. I would like to share my own experience and also show that, far from being a negative choice of career, possibly chosen because of a lack of progression in the system or failure to pass exams, it can be a positive choice and provide a very fulfilling career.

As a medical student at St. George's Hospital Medical School, I really enjoyed the ophthalmology attachment and teaching so I decided that ophthalmology was going to be my choice of career in medicine. I qualified in 1987 and, at that time, it was possible to split the six month house officer post in surgery (now known as foundation post) to do three months of general surgery and three months of ophthalmology. Further years of SHO posts in ophthalmology followed, the equivalent of today's basic surgical training. In those days, most ophthalmic surgeons were still general ophthalmologists performing most types of eye surgery (extracapsular cataract extractions, corneal grafts, DCR, external approach retinal detachment etc) and I soon realised that delivering this wide range of surgery was not for me, so I decided to go down the medical ophthalmology route. I also wanted to work part-time for a short while due to family commitments, so I left the training path after obtaining the Diploma in Ophthalmology (RCS) and FRCOphth. I then moved area to follow my husband who had chosen a GP career.

Initially I did sessions as a Clinical Assistant, then as a Staff Grade Doctor, then I was fortunate to become an Associate Specialist (AS). Sadly this senior Associate Specialist role is now no longer available to new applicants, although those practicing as AS doctors can continue to do so.

Bronwen Attrup

bronwen.attrup@ulh.nhs.uk

1 United Lincolnshire Hospitals NHS Trust, Lincolnshire, UK
I worked in a department with four consultants and three other SAS doctors. Two of my fellow SAS doctors left to become consultants and one emigrated, which left just me. For quite a while, my role was seen as just a service provider, doing repetitive follow up clinics and laser clinics, which became tedious with not much opportunity for me to develop professionally. The trainees had priority for the subspecialty clinics. However, the Lead Clinician at the time was a very good role model for good medical practice and educational support was important in the department. Clinical audit was normal practice in the department so my first appraisal was not as daunting as it could have been.

Things changed with the arrival of a new young medical retina consultant who could see the potential of SAS doctors, or perhaps my potential at least, and my career began to change for the better. We worked together to develop a plan for my clinical and professional development. I learned so much in that first year and still continue to do so. I have a degree of autonomy now in my work and feel trusted to manage new patients and perform virtual clinics, but still know there is support available. I get so much job satisfaction and feel part of the overall team. I am able to work to my full potential and be challenged. I have patients specifically referred for me for laser treatment by my consultant colleagues. I became an appraiser. I have been responsible for the cataract audit over the years which can now be uploaded onto NOD. I had the opportunity to work in clinical research within the department. I also have a teaching role. I am more than happy to help with extra capacity and demand issues.

Five years ago, my Clinical Director suggested me to be the SAS regional representative at the College. This was a real opportunity for me. I was able to see ophthalmology as a much bigger picture and soon realised how much hard work College staff and consultants/SAS doctors input at the Royal College of Ophthalmologists. I was fortunate and proud to be the SAS Committee Chair for the past three years which allowed me to sit on Council and Professional Standards Committee. 
There is so much support and work ongoing at the College for the continuing professional development of SAS doctors, before and following the recent SAS survey. The Professional Standards, SAS, Education, Training and Workforce committees are all involved. The College has written a statement (like some other Royal Colleges) which supports the possible re-introduction of the Associate Specialist grade by the NHS. I also feel encouraged that there are some hospital trusts now offering organised SAS training posts for CESR, with built in subspecialty rotations, planned development programmes and educational assessments and appraisals similar to those for trainees, which hopefully will improve recruitment, give better job satisfaction and support professional development for SAS doctor careers in ophthalmology. All these positive developments will hopefully allow SAS doctors to successfully achieve becoming a consultant if they wish it, but also, if not, to allow them to contribute to capacity issues and provide high quality more autonomous care working at the peak of their potential.

Acknowledgements I would like to thank all ophthalmologists with whom I have worked, the RCOphth SAS committee, and Miss Melanie Hingorani, Chair of Professional Standards committee for her support.

\section{Compliance with ethical standards}

Conflict of interest The authors declare that they have no conflict of interest.

Publisher's note: Springer Nature remains neutral with regard to jurisdictional claims in published maps and institutional affiliations. 